\title{
В.С. Сохина
}

ГОО ВПО «Донецкий национальный медицинский университет имени М. Горького», Донецк

\section{ПРОГНОСТИЧЕСКАЯ МОДЕЛЬ РАННЕЙ ДИАГНОСТИКИ ПРОГРЕССИРОВАНИЯ ХРОНИЧЕСКОЙ ИШЕМИИ МОЗГА}

Прогноз развития цереброваскулярной патологии остается одной из наиболее актуальных проблем неврологии, в связи с чем обсуждаются факторы риска прогрессирования хронической ишемии мозга (ХИМ) и развития острого нарушения мозгового кровообращения [1]. ХИМ характеризуется двумя качественными особенностями: постепенным развитием (часто с длительным периодом клинически «скрытого» течения) и мультифокальными поражениями мозга. Диагностика сосудистого поражения головного мозга основана на выявлении клиниконеврологических и нейропсихологических нарушений. Использование ультразвуковой допплерографии, магнитно-резонансной или компьютерной томографии для анализа регионарной гемодинамики, характера и локализации очагов поражения головного мозга только частично соотносится с наличием, типом и выраженностью нейропсихологических нарушений. Выход из положения видится в разработке информативных методов ранней диагностики стадий ХИМ и создании на этой основе моделей прогноза риска прогрессирования заболевания.

\section{ЦЕЛЬ ИССЛЕДОВАНИЯ}

На основании анализа функциональной активности рецепторов тромбоцитов (Тц) определить их диагностическую значимость в развитии различных стадий ХИМ и разработать модель прогнозирования риска развития 3-й стадии ХИМ.

\section{МАТЕРИАЛ И МЕТОДЫ}

Исследование носило проспективный характер и включало 107 пациентов с клиническими и нейровизуализационными признаками ХИМ; обследованный контингент представлен 37 мужчинами и 70 женщинами в возрасте от 41 до 93 лет (средний возраст $-65,7 \pm 1,1$ года). Критерии включения пациентов в исследование: (a) наличие объективно выявленных неврологических и психических симптомов, которые имеют тенденцию к прогрессированию; наличие при- знаков цереброваскулярного заболевания, в том числе факторов риска (сахарный диабет, атеросклероз, артериальная гипертензия, нарушения сердечного ритма и другие); (б) наличие анамнестических или инструментально подтвержденных признаков поражения мозговых сосудов и/или вещества мозга; (в) наличие причинноследственной связи между клиническими проявлениями и цереброваскулярным заболеванием при условии доказанных сосудистых изменений вещества мозга, которые соответствуют основным клиническим проявлениям заболевания; (г) наличие когнитивного дефекта или двигательных нарушений подкорково-лобного типа (лобная дисбазия/дизартрия) с учетом особенностей течения, указывающих на сосудистый генез симптомов (постепенное прогрессирование); (д) отсутствие признаков, характерных для других заболеваний, которые способны объяснить клиническую картину. Выраженность когнитивного дефицита оценивали по краткой шкале оценки психического статуса - MMSE. Больным проводили ультразвуковое дуплексное сканирование (УЗДС) брахиоцефальных артерий (ультразвуковая система GE MedicalSystems VIVID 7), а также исследование головного мозга с использованием методов магнитнорезонансной (Philips «Ingenia» $1.5 \mathrm{~T}$ ) и компьютерной томографии (64 срезовый аппарат КТ Philips, Brilliance 16).

При ХИМ изменяется экспрессия пуриновых (Р2X, Р2Y) рецепторов, ангиотензиновых AT1-рецепторов, $\alpha 2$-адренорецепторов и ФАТрецепторов на нейронах, глиальных клетках и эндотелии сосудов, а также на мононуклеарах, мигрирующих в нервную ткань мозга [2, 3]. Поскольку реактивность организма обеспечивается рецепторами на клетках-мишенях в разных тканях, то реакция рецепторов на лейкоцитах и Тц может быть индикатором системно-

(c) В.С. Сохина, 2020

(c) Университетская Клиника, 2020 
го действия гуморальных факторов. В этой связи активность рецепторов Тц отражает не только присутствие определенного фактора риска ХИМ, но и позволяет верифицировать конкретные патогенетические механизмы реализации его эффекта.

Анализ функционального состояния Тц проводили in vitro на момент госпитализации пациентов до начала консервативной терапии. Из периферической крови путем центрифугирования выделяли обогащенную тромбоцитами плазму. В пробе содержание тромбоцитов в 1 мкл составляло 200 000 20 000.В исследовании применяли агонисты рецепторов, участвующих в патогенезе ХИМ, в частности АДФ (аденозиндифосфат, лиганд пуриновых Р2Ү-рецепторов), ангиотензин-2 (лиганд АТ1-рецептора), фактор активации тромбоцитов (лиганд ФАТрецептора), адреналин (неселективный лиганд $\alpha 2$-адренорецепторов), коллаген IV-типа (лиганд GPVI-рецептора). Оценку агрегации тромбоцитов (АТц) проводили турбидиметрическим методом на анализаторе ChronoLog (США). Характеристика кластеров функциональной активности рецепторов Тц отражает степень тяжести ХИМ и используется для дифференцировки стадий заболевания. У всех обследованных пациентов получено информированное согласие на участие в исследовании.

Статистический анализ осуществлялся с использованием пакета EZR v.1.35 (Saitama Medical Center, Jichi Medical University, Saitama, Japan), представляющего собой графический интерфейс к R (The R Foundation for Statistica Computing, Vienna, Austria). Прогнозирование риска развития 3-й стадии ХИМ осуществлялось по сравнению с 1-2 стадией заболевания. Адекватность регрессионной модели оценивали по скорректированному показателю детерминации (R2adjusted).

\section{РЕЗУЛЬТАТ Ы И ОБСУЖДЕНИЕ}

При проведении математического анализа обнаружена связь каждой стадии ХИМ со значением показателей функциональной активности исследованных рецепторов. Для уточнения этой связи и определения набора признаков, тесно связанных со всеми стадиями ХИМ, был использован метод парного корреляционного анализа и метод построения моделей многофакторной линейной регрессии (обобщенные регрессионные модели). В таблице 1 приведены значения показателей парной корреляции (показатель ранговой корреляции Спирмена) для рассматриваемых признаков. Выявлена сильная положительная связь показателя АТц-индуцированной АДФ со стадией ХИМ. Средней силы связь установлена между стадией ХИМ и активностью АТ1рецепторов, $\alpha 2$-адренорецепторов, и слабая связь выявлена между стадией заболевания и активностью ФАТ-рецепторов. Если сравнить силу связи стадии ХИМ с функциональной активностью рецепторов, то она уменьшается в следующем направлении: активность Р2Y-рецептора $>$ активности $\alpha 2$-адренорецептора = активности AT1-рецептора >активности ФАТ-рецептора. Таким образом, независимо от стадии ХИМ пять причин могут быть отнесены к факторам риска развития заболевания: гипоксия/ишемия мозга, которая сопровождается повышением уровня в крови пуринов (АТФ, АДФ и аденозина); артериальная гипертензия как следствие активации ренин-ангиотензиновой системы (РАC) и симпато-адреналовой системы (САС); длительность сахарного диабета (СД) и системная воспалительная реакция, направленная на активацию и миграцию лейкоцитов посредством ФАТ.

Анализ корреляционной связи активности AT1-рецепторов I типа, P2Y-(P2Y1, P2Y12) пуриновых рецепторов, $\alpha 2$-адренорецептора, ФАТ-рецептора и GP-VI рецептора открывает возможность конкретизировать причинноследственные взаимосвязи, лежащие в основе патогенеза ХИМ (табл. 2.). Так, наличие корреляции между активностью АТ1-рецепторов и Р2Yрецептора свидетельствует о значимости взаимосвязи РАС и ХИМ в патогенезе ХИМ. Такое взаимодействие представляет особый интерес, поскольку у лиц пожилого возраста отмечается (а) димеризация АТ1- и Р2Y-рецепторов, которая

Корреляционная матрица основных характеристик ХИМ

Таблица 1.

и функциональной активности рецепторов тромбоцитов

\begin{tabular}{llcccccc}
\hline & Статистика & $\begin{array}{c}\text { ДлительностьСД } \\
\text { (годы) }\end{array}$ & ГГ & AT1-R & P2Y-R & $\alpha 2-\mathrm{AR}$ & ФАТ-R \\
\hline \hline \multirow{2}{*}{$\begin{array}{l}\text { Стадия } \\
\text { ХИМ }\end{array}$} & $\begin{array}{l}\text { Коэффициент ранговой } \\
\text { корреляции Спирмена }\end{array}$ & 0,320 & 0,120 & 0,554 & 0,874 & 0,610 & 0,489 \\
\cline { 2 - 8 } & $\begin{array}{l}\text { Уровень 3начимости } \\
\text { различия от 0, p }\end{array}$ & $<0,001$ & 0,229 & $<0,001$ & $<0,001$ & $<0,001$ & $<0,001$ \\
\hline
\end{tabular}

Примечание: Длительность СД - 1балл за 1 год; ГГ - гипергликемия; AT1-R - ангиотензиновые рецепторы I типа; P2Y-R (P2Y1 P2Y12-) - пуриновые рецепторы; $\alpha 2-\mathrm{AR}$ - $\alpha 2$-адренорецепторы; ФАТ-R - рецепторы к фактору активации тромбоцитов. 
Таблица 2.

Корреляционная матрица отражающая взаимосвязь функциональной активности рецепторов тромбоцитов у пациентов с ХИМ (в анализ включены пациенты с 1-3 стадиями заболевания)

\begin{tabular}{lccccc}
\hline \multicolumn{1}{c}{ Рецепторы } & AT1-R & P2Y-R & ФAT-R & $\alpha 2-A R$ & GP-VI R \\
\hline \hline AT1-R & & 0,640 & 0,309 & & 0,393 \\
\hline P2Y-R & 0,640 & - & 0,540 & 0,524 & 0,632 \\
\hline$\alpha 2-A R$ & - & 0,524 & 0,446 & - & 0,527 \\
\hline ФAT-R & 0,309 & 0,540 & - & 0,446 & 0,733 \\
\hline GP-IV R & 0,393 & 0,632 & 0,733 & 0,527 & - \\
\hline
\end{tabular}

Примечания: приведены значения показателей ранговой корреляции Спирмена, которые имеют статистически значимую разницу от 0 (p <0,05); AT1-R - ангиотензиновые рецепторы I типа; P2Y-R - пуриновые рецептоpы; $\alpha 2-\mathrm{AR}$ - $\alpha 2$-адренорецепторы; ФАT-R - рецепторы к фактору активации тромбоцитов; GP-VIR - рецепторы к коллагену IVтипа.

обеспечивает стойкую АГ при активации РАС [4], (б) ремоделирование сосудистой стенки, связанное с эффектами Ан-2 [5]. Данный факт объясняет, почему возраст может быть фактором риска гипертонии. Активация РАС является фактором риска прогрессирования ХИМ не только вследствие повышения АД, но и в силу увеличения проницаемости гемато-энцефалического барьера (ГЭБ) и нарушения когнитивных функций [6].

Анализ силы корреляционной связи Р2Yрецептора свидетельствует о равной степени (средняя сила) взаимодействия с АТ1рецептором, GP-VI рецептором, ФАT-рецептором и $\alpha 2-$ адренорецептором. Следовательно, реактивность P2Y-рецептора на клетках мишенях потенцируется как системными механизмами с участием PAC и САС, так и локальными механизмами, сопровождающими развитие нейровоспаления. Известно, что пуринергическая сигнальная система, включающая АТФ, АДФ и аденозин, а также экспрессия разных подтипов рецепторов Р1 и Р2 контролирует воспалительные реакции в нервной системе [7]. Высвобождение цитокинов, активация и миграция микроглии и изменение функции астроглии являются ключевыми механизмами нейровоспалительного ответа [8]. Значимость активации пуриновых Р2Y-рецепторов (Р2Y1 и Р2Y12) в патогенезе ХИМ определяется участием в функционировании различных глиальных и нейрональных модулей нервной системы [9], в поддержании паракринной связи микроглия-астроциты[10], в обеспечении микроглиального фагоцитоза [11], в экспрессии генов микроглии, связанных с высвобождением провоспалительных цитокинов (ИЛ-1 $\beta$, ИЛ-6 и ФНО- $\alpha$ ) [12].
На первом этапе построения математической модели проанализирована связь риска развития ХИМ 3-й стадии с 7 факторными признаками: длительностью СД, концентрацией глюкозы в крови, активностью АТ1-рецептора, пуриновых Р2Ү-рецепторов, $\alpha 2$-адренорецептора, ФАТ-рецептора и GPVI-рецептора к коллагену. При этом использовали метод построения однофакторной модели логистической регрессии. Учитывались показатели, зарегистрированные у 62 пациентов с ХИМ 1 и 2 стадии (выходная переменная $\mathrm{Y}=0$ ) и 45 пациентов с СД 3-й стадии (выходная переменная $\mathrm{Y}=1$ ), причем у 67 пациентов ХИМ был ассоциирован с СД 2 типа, у 40 пациентов имела место ХИМ без СД. Проведенный анализ свидетельствует о наличии связи риска развития 3-й стадии ХИМ с каждым из 7-ми представленных признаков. Установлено, что риск тяжелой стадии ХИМ возрастает при увеличении длительности СД 2 типа (p = $0,001)-$ ОШ = 1,2 (95\% ДИ 1,1-1,3) на каждый год СД; повышении концентрации глюкозы в крови $(\mathrm{p}=0,014)-$ ОШ = 1,2 (95\% ДИ 1,0-1,4) на каждую единицу (ммоль/л) прироста данного показателя; увеличении активности Р2Y-рецептора $(\mathrm{p}<0,001)-$ ОШ = 1,4 (95\% ДИ 1,2-1,6) на каждую единицу прироста показателя (на 1\% АТциндуцированной АДФ); увеличении активности GPVI-рецептора ( $<<0,001)$ - ОШ = 1,3 (95\% ДИ 1,2-1,4) на каждую единицу прироста показателя (на $1 \%$ повышения АТц-индуцированной коллагеном); увеличении активности $\alpha 2$ адренорецептора ( $<<0,001)$ - ОШ = 1,3 (95\% ДИ $1,2-1,5)$ на каждую единицу прироста показателя (на 1\% повышения АТц-индуцированной адреналином) и увеличении активности ФАТрецептора $(\mathrm{p}<0,001)-$ ОШ = 1,2 (95\% ДИ 1,1-1,3) 
на каждую единицу прироста (на 1\% повышения АТц-индуцированной ФАТ) данного показателя.

В наибольшей степени риск 3-й стадии ХИМ был связан с уровнем АДФ-индуцированной АТц (активностью Р2Y-рецептора), поскольку площадь под кривой операционных характеристик для модели, рассчитанной на основании значений данного индикатора, достигала 0,968 (AUC=0,968; 95\% ДИ 0,92-0,99). Данный факт свидетельствует о высокой диагностической значимости предлагаемого теста для выявления больных с ХИМ 3-й стадии. При выборе оптимального порога принятия решения (по Youden Index) установлен критический порог АДФ-индуцированной АТц (АДФсrit) = 67\%. При значении показателя АДФсrit > 67\% у пациента имела место 3-я стадия ХИМ, при значении показателя АДФсrit $\leqslant 67 \%$ прогнозировалась ХИМ 1-2 стадии. Для выбранного порога чувствительность предлагаемого диагностического теста составляет 88,8\% (95\% ДИ 75,9-96,3) и специфичность - 91,9\% (95\% ДИ 82,2-97,3); прогностическая ценность положительного результата - 88,8\% (95\% ДИ 77,4-94,9), прогностическая ценность отрицательного результата - 91,9\% (95\%ДИ 83,3-96,3).

\section{В Ы В ОД Ы}

1. Полученные результаты подтверждают возможность участия пуринергической системы мозга в патогенезе ХИМ, а следовательно, сигнализация Р2Y-рецептора может рассматриваться как потенциальная терапевтическая мишень, позволяющая ограничивать нейровоспаление.

2. Впервые доказана возможность прогнозирования риска прогрессированияХИМ на основании экспресс-диагностики активности Р2Yрецептора тромбоцитов, которая регулируется накоплением нуклеотидов при гипоксии/ишемии мозга. При значении показателя агрегации Тц индуцированной АДФ > 67\% у пациента имела место 3-я стадия ХИМ, при значении данного показателя $\leqslant 67 \%$ прогнозировалась ХИМ 1-2 стадии заболевания. Чувствительность предлагаемого диагностического теста составляет 88,8\% (95\% ДИ 75,9-96,3), и специфичность 91,9\% (95\% ДИ 82,2-97,3).

3. Разработка моделей, основанных на анализе активности рецепторов Тц, представляется перспективной, поскольку может привести к улучшению профилактических и терапевтических стратегий при ХИМ.

\section{В.С. Сохина}

ГОО ВПО «Донецкий национальный медицинский университет имени М. Горького», Донецк

\section{ПРОГНОСТИЧЕСКАЯ МОДЕЛЬ РАННЕЙ ДИАГНОСТИКИ ПРОГРЕССИРОВАНИЯ ХРОНИЧЕСКОЙ ИШЕМИИ МОЗГА}

\begin{abstract}
Цель - определить диагностическую значимость функциональной активности рецепторов тромбоцитов при прогрессировании хронической ишемии мозга и разработать модель прогнозирования риска развития 3-й стадии заболевания. Исследование носило проспективный характер и включало 107 пациентов с клиническими и нейро-визуализационными признаками ХИМ. Обследование проводилось до начала лечения и включало клинико-неврологическое и нейропсихологическое исследование; ультразвуковую допплерографию брахиоцефальных артерий, компьютерную и магнитно-резонансную томографию головного мозга. Для изучения функциональной активности рецепторов тромбоцитов использовали агонисты рецепторов, участвующих в патогенезе ХИМ, в частности АДФ (лиганд пуриновых Р2Ү-рецепторов), ангиотензин-2 (лиганд АТ1-рецептора), фактор активации тромбоцитов (лиганд ФАТ-рецептора), адреналин (неселективный лиганд $\alpha 2$-адренорецепторов) коллаген IV типа (лигпанд GPVI-рецептора). Оценку агрегации тромбоцитов проводили турбидиметрическим методом на анализаторе ChronoLog (США) Для анализа связи стадий ХИМ со значением активности рецепторов тромбоцитов использованы ме-
\end{abstract}

тоды парного корреляционного анализа и построения моделей линейной регрессии. Выявлены 7 значимых факторов риска, тесно связанных со стадией ХИМ. В наибольшей степени риск 3-й стадии хронической ишемии мозга был связан с уровнем АДФиндуцированной агрегации тромбоцитов (активностью Р2Y-рецептора). Площадь под кривой операционных характеристик для модели, рассчитанной на основании значений данного индикатора, достигала 0,968 (AUC=0,968; 95\% ДИ 0,92-0,99), что свидетельствует о высокой диагностической значимости предлагаемого теста. Для выбранного критического порога АДФ-индуцированной агрегации тромбоцитов чувствительность предлагаемого диагностического теста составляет $88,8 \%(95 \%$ ДИ $75,9-96,3)$ и специфичность - 91,9\% (95\% ДИ 82,2-97,3). Выявление лиц высокого риска прогрессирования ХИМ на более ранней стадии с использованием модели может привести к улучшению профилактических и терапевтических методов лечения пациентов с цереброваскулярной патологией.

Ключевые слова: хроническая ишемия мозга, рецепторы тромбоцитов, математические модели прогнозирования. 


\section{V.S. Sokhina}

\section{SEI HPE «M. Gorky Donetsk National Medical University», Donetsk}

\section{PREDICTION MODEL OF CHRONIC BRAIN ISCHEMIA EARLY DIAGNOSTICS}

The aim is to determine the diagnostic significance of the platelet receptors functional activity with the progression of chronic brain ischemia (CBI) and to develop a model for predicting the risk of developing III stage of the disease. The study had a prospective character and 107 patients were included with clinical and neuro-imaging signs of CBI. The examination was carried out before treatment and included a clinical neurological and neuropsychological study, Doppler ultrasound of the brachiocephalic arteries, computed tomography and magnetic resonance imaging of the brain. To study the functional activity of platelet receptors, agonists of receptors involved in the pathogenesis of CBI were used, in particular: ADP (purine P2Y-receptors ligand), angiotensin-2 (AT1-receptor ligand), platelet-activating factor (PAFreceptor ligand), adrenalin (non-selective ligand $\alpha 2$ adrenergic receptors), type IV collagen (GPVI-receptor ligand). Platelet aggregation (PA) was evaluated by a turbidimetric method on an ChronoLog analyzer (USA). To analyze the relationship between the stages of CBI and the value of receptor activity, methods of constructing linear regression models were used. 7 significant risk factors were identified that are strongly associated with the stage of CBI. To the greatest degree, CBI III stage risk was associated with the level of ADP-induced platelet aggregation (P2Y receptor activity). The area under the curve of operational characteristics for the model calculated on the basis of the values of this indicator reached 0,968 (AUC $=0.968$; 95\% CI 0.92-0.99), which indicates the high diagnostic significance of the proposed test. For the selected critical threshold of an ADP-induced platelet aggregation, the sensitivity of the proposed diagnostic test is $88.8 \%$ (95\% CI 75.9-96.3) and specificity $91.9 \%$ (95\% CI 82.2-97.3). Identification of individuals with high risk of progression of CBI at an earlier stage using the model can lead to improving preventive and therapeutic methods for treating patients with cerebrovascular pathology.

Key words: chronic brain ischemia, platelet receptors, mathematical prediction models.

\section{ЛИТЕРАТУРА}

1. Zhang S., Zhang W., Zhou G. Extended Risk Factors for Stroke Prevention. J Natl Med Assoc. 2019;111(4):447-456.

2. Brailoiu E., Barlow C.L., Ramirez S.H., Abood M.E., Brailoiu G.C. Effects of platelet-activating factor on brain microvascular endothelial cells. Neuroscience. 2018;377:105-113.

3. O'Connor A.T., Clark M.A. Angiotensin II induces cyclooxygenase 2 expression in rat astrocytes via the angiotensin type 1 receptor. Neuropeptides. 2019;77:101958.

4. Nishimura A., Sunggip C., Tozaki-Saitoh H., Shimauchi T. et al. Purinergic P2Y6 receptors heterodimerize with angiotensin AT1 receptors to promote angiotensin II-induced hypertension. Sci Signal. 2016; 9(411):ra7.

5. Sunggip C., Nishimura A., Shimoda K., Numaga-Tomita T., Tsuda M., Nishida M. Purinergic P2Y6 receptors: A new therapeutic target of age-dependent hypertension. Pharmacol Res. 2017;120:51-59.

6. Biancardi V.C., Stern J.E. Compromised blood-brain barrier permeability: novel mechanism by which circulating angiotensin II signals to sympathoexcitatorycentres during hypertension. J Physiol. 2016;594(6):1591-600.

7. Beamer E., Gölöncsér F., Horváth G., Bekő K., Otrokocsi L. et al. Purinergic mechanisms in neuroinflammation: An update from molecules to behavior. Neuropharmacology. 2016;104:94-104.

8. James G., Butt A.M. P2Y and P2X purinoceptor mediated $\mathrm{Ca} 2+$ signalling in glial cell pathology in the central nervous system. Eur J Pharmacol. 2002;447(2-3):247-260.

9. Miras-Portugal M.T., Queipo M.J., Gil-Redondo J.C., Ortega F1, Gómez-Villafuertes R.et al. P2 receptor interaction and signalling cascades in neuroprotection. Brain Res Bull. 2019;151:74-83.

10. Quintas C., Vale N., Gonçalves J., Queiroz G. Microglia P2Y13 receptors prevent astrocyte proliferation mediated by P2Y1 receptors. Front Pharmacol. 2018;9:418.

11. Xu Y., Hu W., Liu Y., Xu P., Li Z. P2Y6 Receptor-Mediated Microglial Phagocytosis in Radiation-Induced Brain Injury. MolNeurobiol. 2016;53(6):3552-3564.

12. LiuP.W.,YueM.X., ZhouR., NiuJ., HuangD.J.etal. P2Y12 and $\mathrm{P} 2 \mathrm{Y} 13$ receptors involved in ADP $\beta$ s induced the release of IL-1 $\beta$, IL- 6 and TNF- $\alpha$ from cultured dorsal horn microglia. J Pain Res. 2017;10:1755-1767.

\section{REFERENCES}

1. Zhang S., Zhang W., Zhou G. Extended Risk Factors for Stroke Prevention. J Natl Med Assoc. 2019;111(4):447-456.

2. Brailoiu E., Barlow C.L., Ramirez S.H., Abood M.E., Brailoiu G.C. Effects of platelet-activating factor on brain microvascular endothelial cells. Neuroscience. 2018;377:105-113.

3. O’Connor A.T., Clark M.A. Angiotensin II induces cyclooxygenase 2 expression in rat astrocytes via the angiotensin type 1 receptor. Neuropeptides. 2019;77:101958.

4. Nishimura A., Sunggip C., Tozaki-Saitoh H., Shimauchi T. et al. Purinergic P2Y6 receptors heterodimerize with angiotensin AT1 receptors to promote angiotensin II-induced hypertension. Sci Signal. 2016; 9(411):ra7.

5. Sunggip C., Nishimura A., Shimoda K., Numaga-Tomita T., Tsuda M., Nishida M. Purinergic P2Y6 receptors: A new therapeutic target of age-dependent hypertension. Pharmacol Res. 2017;120:51-59.

6. Biancardi V.C., Stern J.E. Compromised blood-brain barrier permeability: novel mechanism by which circulating angiotensin II signals to sympathoexcitatorycentres during hypertension. J Physiol. 2016;594(6):1591-600.

7. Beamer E., Gölöncsér F., Horváth G., Bekő K., Otrokocsi L. et al. Purinergic mechanisms in neuroinflammation: An update from molecules to behavior. Neuropharmacology. 2016;104:94-104.

8. James G., Butt A.M. P2Y and P2X purinoceptor mediated $\mathrm{Ca} 2+$ signalling in glial cell pathology in the central nervous system. Eur J Pharmacol. 2002;447(2-3):247-260.

9. Miras-Portugal M.T., Queipo M.J., Gil-Redondo J.C., Ortega F1, Gómez-Villafuertes R.et al. P2 receptor interaction and signalling cascades in neuroprotection. Brain Res Bull. 2019;151:74-83.

10. Quintas C., Vale N., Gonçalves J., Queiroz G. Microglia P2Y13 receptors prevent astrocyte proliferation mediated by P2Y1 receptors. Front Pharmacol. 2018;9:418.

11. Xu Y., Hu W., Liu Y., Xu P., Li Z. P2Y6 Receptor-Mediated Microglial Phagocytosis in Radiation-Induced Brain Injury. MolNeurobiol. 2016;53(6):3552-3564.

12. LiuP.W.,YueM.X., ZhouR., NiuJ., HuangD.J.etal. P2Y12 and P2Y13 receptors involved in ADP $\beta$ s induced the release of IL-1 $\beta$, IL- 6 and TNF- $\alpha$ from cultured dorsal horn microglia. J Pain Res. 2017;10:1755-1767. 